\title{
Sudden Cardiac Death: Clinical Perspectives from the University of Maiduguri Teaching Hospital, Nigeria
}

\author{
Mohammed Abdullahi Talle ${ }^{*}$, Aimé Bonny², Bukar Bakki' ${ }^{1}$ Faruk Buba1, \\ Charles Oladele Anjorin' ${ }^{1}$, Haruna Yusuph ${ }^{1}$, Adama Kane ${ }^{3}$ \\ ${ }^{1}$ University of Maiduguri Teaching Hospital, Maiduguri, Nigeria \\ ${ }^{2}$ Teaching Hospital Laquintinie, University of Douala, Douala, Cameroon \\ ${ }^{3}$ Service de Cardiogie, Centre Hospitalier le Dantec, Dakar, Senegal \\ Email: ${ }^{*}$ abdultalle@yahoo.com
}

Received 28 March 2015; accepted 12 May 2015; published 15 May 2015

Copyright (C) 2015 by authors and Scientific Research Publishing Inc.

This work is licensed under the Creative Commons Attribution International License (CC BY). http://creativecommons.org/licenses/by/4.0/

\section{(c) (i) Open Access}

\section{Abstract}

Despite tremendous advances in the management of cardiovascular diseases and cardiac arrest, there is paucity of information regarding sudden cardiac death in sub-Saharan Africa. We present a two-year review of sudden cardiac death cases among patients managed at a Nigerian tertiary hospital. Patients admitted from January 2012 to December 2013 were prospectively followed-up and cases of sudden cardiac death identified. Diagnosis was based on records of events preceding death, direct interview of attending physician/nurses, and family members/eye witnesses for out-of-hospital sudden cardiac death. Causes of death were obtained from the death certificates for cases of in-hospital events. Three hundred and eighty eight $(M: F=1: 1.3)$ patients with a mean age of 42.22 \pm 19.30 years were admitted into the cardiac unit during the period, out of whom 56 $(14.4 \%)$ died. Twenty three $(\mathbf{4 1 . 1 \% )})$ were classified as sudden cardiac death. The predominant etiology was ischemic cardiomyopathy $(39.1 \%)$, followed by peripartum cardiomyopathy $(21.7 \%)$ and dilated cardiomyopathy (17.4\%). Rheumatic heart disease was diagnosed in $17.4 \%$, while $4.3 \%$ had pulmonary hypertension. Nineteen $(82.6 \%)$ of the subjects had congestive cardiac failure. Hypokalemia and hypocalcaemia were recorded in $2(8.7 \%)$ patients who developed prolongation of the QT interval following commencement of diuretics. Chest-compression- only cardiopulmonary resuscitation was attempted in $12(52.1 \%)$ with a success rate of $8.3 \%$. Sudden cardiac death is common among our patients admitted with cardiovascular diseases. The most common etiology is ischemic cardiomyopathy, followed by peripartum cardiomyopathy. Most of the victims were young, and there were no optimum resuscitative measures.

${ }^{*}$ Corresponding author.

How to cite this paper: Talle, M.A., Bonny, A., Bakki, B., Buba, F., Anjorin, C.O., Yusuph, H. and Kane, A. (2015) Sudden Cardiac Death: Clinical Perspectives from the University of Maiduguri Teaching Hospital, Nigeria. World Journal of Cardiovascular Diseases, 5, 95-106. http://dx.doi.org/10.4236/wjcd.2015.55013 
Keywords

Sudden Cardiac Death, Nigeria, Etiology, Prevalence, Outcome

\section{Introduction}

The burden of disease due to cardiovascular causes is on the rise globally, especially in the developing countries experiencing epidemiological transition. This is projected to result in increased morbidity and mortality [1]. Up to half of all cardiac death cases are attributable to Sudden Cardiac Death (SCD), defined as natural death from cardiac causes, heralded by abrupt loss of consciousness within 1 hour of the onset of an acute change in cardiovascular status with, or without a preexisting heart disease [2] [3].

Sudden cardiac death accounts for about $20 \%$ of all mortalities in the western world [4]. About 450,000 people die from SCD in the USA alone, with an annual incidence of $0.1 \%-0.2 \%$ [5]. This is similar to what obtains in other western industrialized nations where coronary artery disease (CAD) is common. More than 7,000,000 lives are estimated to be lost to SCD per year [6]. The changing dietary and lifestyle habit in developing nations is leading to a trend towards increasing incidence of SCD [7]. The incidence in Nigeria remains largely unknown with variable rates being reported from different postmortem studies.

Non-ischemic cardiomyopathy, congenital and genetic arrhythmic syndromes are among the leading causes in young adults. The available Nigerian studies have consistently revealed hypertensive heart disease (HHD) as the leading etiology [8]-[10]. Studies from Ile-Ife revealed dilated cardiomyopathy (DCM) as the etiology in 6\% of victims whereas ischemic heart disease (IHD) accounted for $4 \%$ [8]. A higher prevalence of $9.0 \%$ was reported for myocardial infarction among the victims of SCD in Jos [11]. The most common cause of SCD in the western society is CAD, particularly among the middle aged and elderly population [12].

Survival following sudden cardiac arrest has improved especially among the general population of industrialized countries with the advent of automated external defibrillator (AED) and organized emergency response team. The improved care of patients with cardiovascular disorders, as well as concerted efforts at prevention has led to a trend towards reduced incidence of SCD. However, despite the escalating burden of CVD in developing nations, Nigeria inclusive, the trend is not by any means matched with improved preventive and treatment strategies towards reduction of SCD. This study was aimed at determining the prevalence, etiology and outcomes of sudden cardiac arrest and cardiac death among patients presenting with cardiac diseases at the University of Maiduguri Teaching Hospital (UMTH) over a two-year period.

\section{Methods}

The study population was made of patients admitted with congestive cardiac failure of various etiologies including rheumatic heart disease (RHD), acute pulmonary edema, cardiac arrhythmias and myocardial infarction (MI) from January 2012 through December 2013. All patients admitted during the study period were prospectively followed-up during hospitalization and after discharge. Relevant demographic information was obtained using a structured questionnaire at the time of first contact, and additional information regarding investigations, treatments received and duration of hospitalization and follow-up were obtained from the case notes. Definition of SCD was based on information gathered from records of events preceding death, direct questioning of attending hospital staff at the time of death and information from family members/eye witness for out of hospital SCD.

Sudden cardiac death was defined as natural death from cardiac causes, heralded by abrupt loss of consciousness within 1 hour of the onset of an acute change in cardiovascular status with, or without a preexisting heart disease (or within 24 hours for un witnessed SCD) [2] [3]. Heart failure and peripartum cardiomyopathy (PPCM) were defined in accordance with the ESC guideline, whilst diagnosis of RHD was based on the proposed World Heart Federation guideline of 2012 [13]-[15]. Myocardial infarction was defined on the basis of chest pain, ECG changes and documentation of wall motion abnormalities on echo.

Details of ECG abnormalities, echocardiograms, serum biochemistry and medications were obtained from the case notes. Ethical clearance was granted by the Research and Ethics committee of the UMTH. Data was analyzed using SPSS version 16 (SPSS Inc., Chicago, IL, USA). Continuous variables were expressed as mean \pm 
SD, and comparison made using Student's t-test. Results are presented using tables, charts and figures.

\section{Results}

A total of 388 patients comprising 171 (44.1\%) males and 217 (55.9\%) females were managed in the cardiac unit during the period under review. Their mean age was $49.01 \pm 18.67$ years. The mean ages of male and female patients were $55.94 \pm 18.23$ years and $43.17 \pm 17.06$ years respectively $(P=0.001)$. Fifty six $(14.4 \%)$ deaths were recorded involving 25 (44.6\%) males and 31 (55.4\%) females.

Twenty three (41.1\%) of all cardiac deaths involving 11 (47.8\%) males and 12 (52.2\%) females were adjudged to be SCD, giving an overall prevalence of 5.9\% for SCD among patients managed in the cardiac unit during the period under review. Fourteen (60.9\%) SCD (male to female ratio of 1:1) occurred in hospital, whilst out-of-hospital SCD was documented in 9 (39.1\%) of patients (male to female ratio of 1:1.2).

The ages of the SCD patients ranged from 18 to 75 years with a median age of 39 years. Mean age of SCD victims was $42.22 \pm 19.30$ years, with males having a mean age of $47.82 \pm 15.68$ compared to $35.25 \pm 20.26$ years for the females $(P=0.113)$. Clinical and demographic characteristic of the SCD cases is illustrated in Table 1.

\subsection{Etiology and Clinical Features}

The various etiologies for SCD are illustrated in Figure 1. Nine cases (39.1\%) of SCD involving 6 (66.7\%) males and 3 (33.3\%) females were attributed to ischemic cardiomyopathy (ICM). Four (44.4\%) ischemic SCD resulted from ST-elevation acute coronary syndrome (STEACS) while 5 (55.6\%) resulted from Non STelevation acute coronary syndrome (NSTEACS). Four (44.4\%) of the subjects with ischemic SCD were 40 years and below. Seventy five percent of SCD resulting from STEACS were observed in males, among whom one was complicated by ventricular septal rupture.

Table 1. Clinical characteristics of the subjects $(n=23)$.

\begin{tabular}{|c|c|c|c|}
\hline Mean age (yrs) & $42.22 \pm 19.30$ & NYHA class & \\
\hline Female & 12 (52.2\%) & I & $3(13.0 \%)$ \\
\hline Location & & II & $11(47.8 \%)$ \\
\hline Hospital & 14 (60.9\%) & III & 8 (34.8\%) \\
\hline Out-of-hospital & $9(31.9 \%)$ & IV & $1(4.4 \%)$ \\
\hline Home & $7(77.8 \%)$ & Medication & \\
\hline Public place & $2(22.2 \%)$ & ACE inhibitors & 22 (95.7\%) \\
\hline Symptoms experienced & & Beta blockers & $21(91.3 \%)$ \\
\hline Palpitation & 22 (95.7\%) & Furosemide & 21 (91.3\%) \\
\hline Chest pain & $11(47.8 \%)$ & Spironolactone & 16 (69.6\%) \\
\hline Syncope & $4(17.4 \%)$ & Aspirin & $13(56.5 \%)$ \\
\hline Comorbidities & & Digoxin & 14 (60.9\%) \\
\hline Heart failure & 19 (82.6\%) & Statin & $11(47.8 \%)$ \\
\hline Hypertension & $11(47.8 \%)$ & Enoxaparin & $11(47.8 \%)$ \\
\hline Diabetes & $5(21.7 \%)$ & Warfarin & $6(26.1 \%)$ \\
\hline Dyslipidemia & $4(30.8 \%)^{*}$ & Clopidogrel & $5(21.7 \%)$ \\
\hline $\mathrm{AF}$ & $4(17.4 \%)$ & Attempt at resuscitation & \\
\hline Alcohol & $2(8.7 \%)$ & Hospital & $12(85.7 \%)$ \\
\hline Smoking & 2 (8.7\%) & Out-of-hospital & $0(0 \%)$ \\
\hline
\end{tabular}

${ }^{*}$ of available results. AF = Atrial Fibrillation; NYHA = New York Heart Association; ACE = Angiotensin Converting Enzyme. 


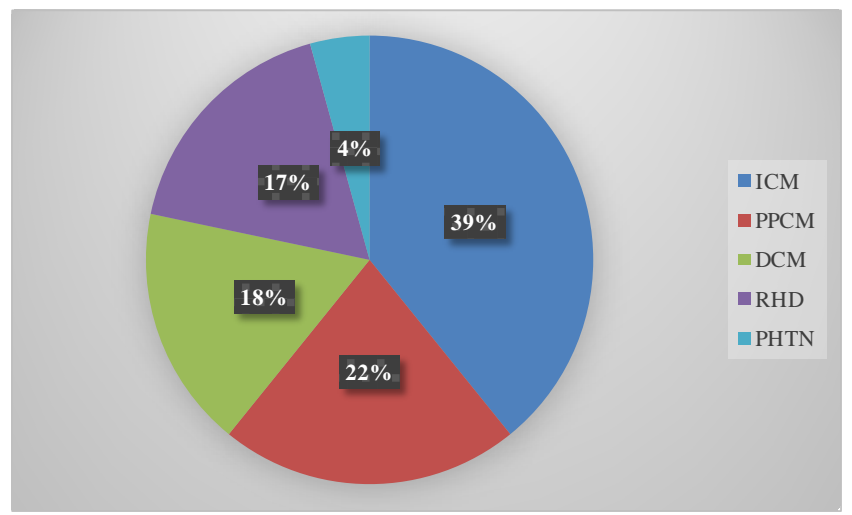

Figure 1. Etiology of sudden cardiac death. ICM = Ischemic Cardiomyopathy; $\mathrm{PPCM}$ = Peripartum Cardiomyopathy; $\mathrm{DCM}=$ Dilated Cardiomyopathy; RHD = Rheumatic Heart Disease; PHTN = Pulmonary Hypertension.

There were 5 (21.7\%) cases of SCD that resulted from PPCM. The ages of the PPCM patients ranged from 18 to 34 years with a mean of $24.20 \pm 6.18$ years. Idiopathic DCM was responsible for $3(13.0 \%)$ cases of SCD in males, while alcoholic cardiomyopathy was responsible in one male patient, aged 35 years. Rheumatic heart disease was diagnosed in 4 (17.4\%), involving 3 (75\%) females with severe mitral regurgitation and aortic valve regurgitation of varying severity, and 1 (25\%) male with mixed mitral valve and aortic valve diseases complicated by a huge vegetation on the aortic valve. Hypokalemia and hypocalcemia were documented in two females with RHD before SCD. Idiopathic pulmonary hypertension was the presumed etiology in one 44-year-old female.

Congestive cardiac failure was diagnosed in 19 (82.6\%) of the victims. Hypertension (or treatment of) was present in $11(47.8 \%)$ while 5 (21.7\%) had diabetes mellitus. Eight (88.9\%) of the patients with ischemic cardiomyopathy (ICM) had hypertension, while 4 (44.4\%) had diabetes mellitus. Combination of hypertension and DM was observed in 4 (44.4\%) of victims with ICM. Eleven (47.8\%) victims had a history of chest pain, while palpitation was documented in 22 (95.7\%). History of prior syncope was documented in 4 (17.4\%). Shortness of breath compatible with NYHA class II was documented in 11 (47.8\%), while 8 (34.8\%) had class III. Three (13.0\%) were in NYHA class I. Chest-compression-only CPR was attempted in 12 (85.7\%) of the in-hospital SCD but only 1 (8.3\%) was successful. None of the out-of hospital cases had CPR.

Result of serum cholesterol was available for 13 (17.5\%) subjects, out of which 4 (30.8\%) had elevated total cholesterol. Atrial fibrillation was present in 4 (17.4\%), while smoking was documented in 2 (8.7\%). Treatment for pulmonary thrombo-embolism was documented in 2 (11.8\%) of the cases. Age-based distribution of the different etiologies for SCD is illustrated in Figure 2.

\subsection{Location and Activities at the Time of Events}

Seven (50\%) in-hospital SCD were cases of ICM, while 3 (21.4\%) were due to idiopathic DCM. Two of the DCM patients died while chatting with family members on the day they were billed for discharge. The third DCM patient died while defecating. Peripartum cardiomyopathy and RHD each contributed 2 (14.3\%) cases of in-hospital SCD. Both cases of in-hospital SCD from RHD were associated with electrolyte abnormality and QT prolongation following use of diuretics. One had a QTc of $755 \mathrm{msec}$ (Figure 3) before she died.

Three out-of-hospital SCD occurred in public place, with one involving a 35-year-old alcoholic DCM patient, who slumped while surfing the internet in a motor mechanic workshop as he awaits the repair of his car; and the second involving a 30-year-old male with RHD and huge vegetation on the aortic valve who collapsed in a grocery shop. The third SCD in public place occurred in a 44-year-old female with pulmonary hypertension, who collapsed in a hotel room when she was about to take supper.

Two breastfeeding mothers with PPCM and one with RHD died in their sleep, having gone to bed in stable conditions. A third PPCM patient died at home following a sudden onset of paroxysmal palpitation.

A 35-year-old male managed with extensive antero-septal myocardial infarction and discharged six months previously collapsed while chatting with family members, and a retired judge previously managed with anterior 


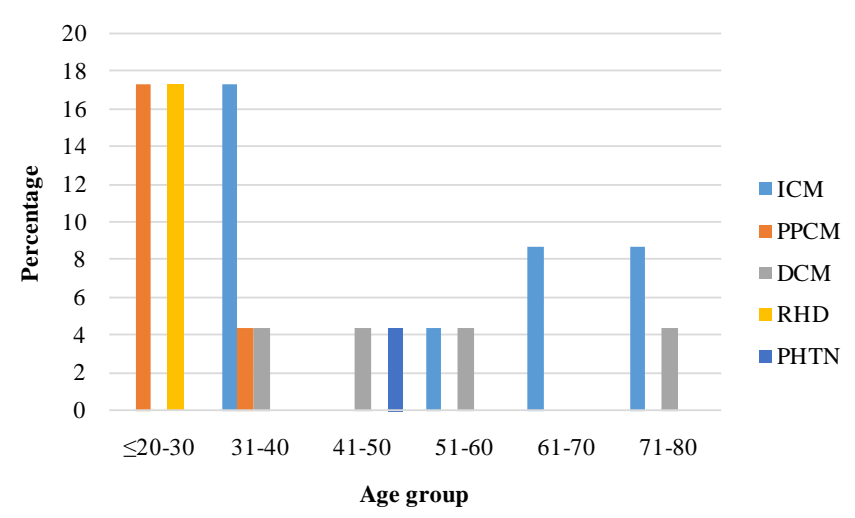

Figure 2. Distribution of etiology by age-group. ICM = Ischemic Cardiomyopathy; PPCM = Peripartum Cardiomyopathy; $\mathrm{DCM}=$ Dilated Cardiomyopathy; RHD = Rheumatic Heart Disease; PHTN = Pulmonary Hypertension.

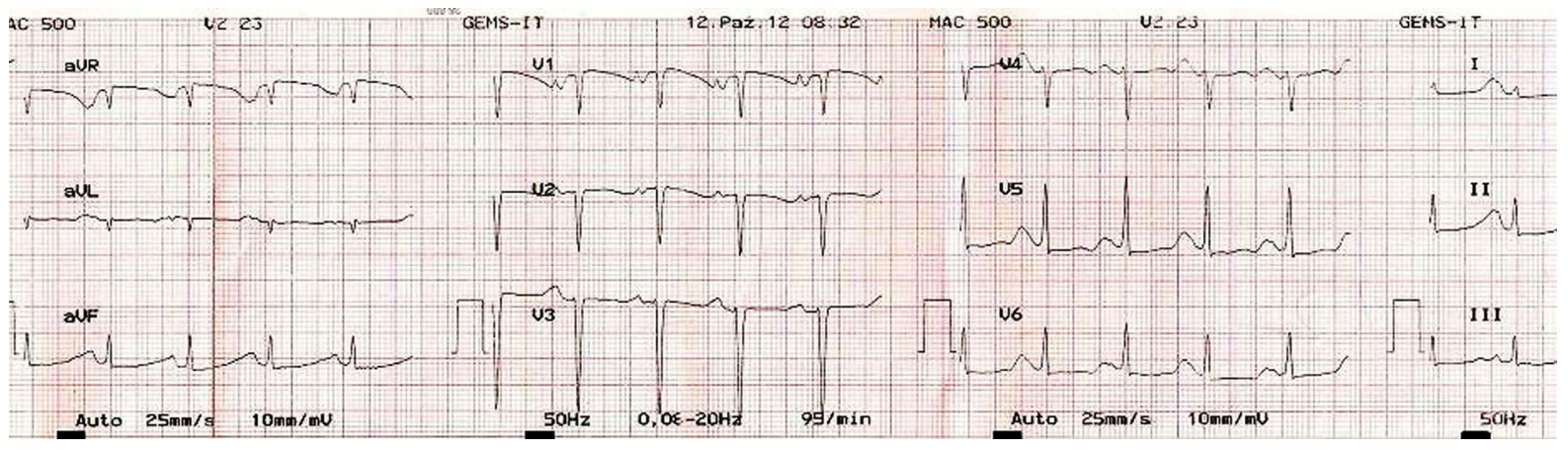

Figure 3. ECG showing prolonged QTc (about $755 \mathrm{msec}$ ) following commencement of heart failure treatment. T-wave is noted to merge with following P-wave, resulting in QT being almost equal to R-R interval. ST segment is depressed in lateral leads.

MI developed chest pain while playing snookers in his country home and collapsed on the way to a hospital.

\subsection{ECG Abnormalities}

The various ECG abnormalities observed are illustrated in Table 2. Twenty one (91.3\%) of the victims had their ECG available for review. Sinus tachycardia was observed in 12 (57.1\%) while non-sustained ventricular tachycardia was seen in 1 (4.8\%). Complete left bundle branch block was recorded in 4 (19.0\%). Left ventricular hypertrophy using the Sokolow's voltage criteria was seen in 8 (38.1\%), whereas left atrial abnormality was observed in 13 (61.9\%). Marked ST Segment depression was documented in 8 (38.1\%), while 3 (14.3\%) had ST segment elevation (2/3 involving antero-septal region). Pathologic Q wave was observed in $2(12.5 \%)$ cases. Eleven (52.4\%) had deep T-wave inversion, whereas prolonged QT interval was observed in 2 (9.5\%) females with RHD and 1 (4.8\%) with PPCM. The patient with the ECG presented in Figure 3 was 22 years old, admitted with PPCM and commenced on conventional treatments of heart failure including diuretics. This was complicated by hypocalcaemia and hypokalemia, resulting in the prolongation of QT and SCD. Results of electrolyte profile were only made available after succumbing to SCD. Atrial fibrillation was documented in 3 (14.3\%), while polymorphic PVC was recorded in 1 (4.8\%). Right ventricular hypertrophy with right axis deviation was noted in one victim with pulmonary hypertension (Figure 4).

\subsection{Echocardiographic Findings}

The result of echo was available for review in 14 (60.9\%). Left ventricular ejection fraction of $35 \%$ or less was observed in 8 (57.1\%) of available records. Dilated left ventricular chamber was observed in 11 (78.6\%), while regional wall motion abnormality was seen in 5 (35.7\%) patients with myocardial infarction. Rheumatic mixed mitral valve disease and aortic regurgitation was observed in 3 (21.4\%) females, whereas mixed mitral (MS/MR) 


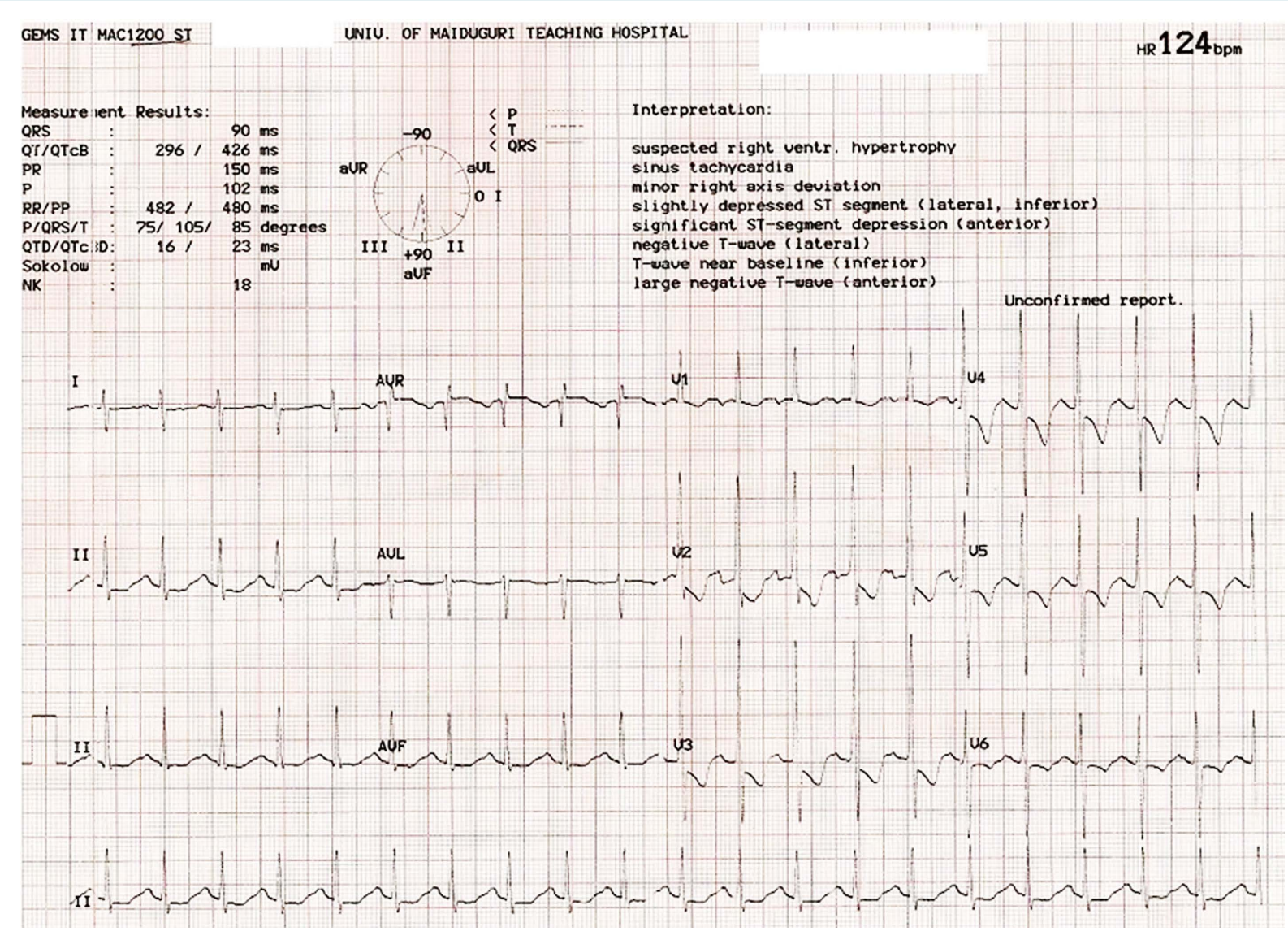

Figure 4. ECG of a victim of SCD from pulmonary hypertension, showing right ventricular hypertrophy and right axis deviation.

Table 2. Electrocardiographic abnormalities.

\begin{tabular}{ll}
\hline Abnormality & Frequency (\%) \\
\hline Sinus tachycardia & $12(57.1)$ \\
Non sustained VT & $1(4.8)$ \\
Polymorphic PVC & $1(4.8)$ \\
Prolonged QT & $3(14.3)$ \\
LBBB & $4(19.0)$ \\
LVH & $8(38.1)$ \\
ST-depression & $8(38.1)$ \\
ST-elevation & $3(14.3)$ \\
Pathologic Q-waves & $2(9.5)$ \\
AF & $3(14.3)$ \\
\hline
\end{tabular}

VT = Ventricular tachycardia; PVC = Premature Ventricular Complex; LBBB = Left Bundle Branch Block; LVH = Left Ventricular Hypertrophy; AF $=$ Atrial Fibrillation.

and aortic (AS/AR) valve disease complicated by vegetation on aortic valve was recorded in 1 (7.1\%) male victim. Left ventricular thrombus and mitral annular calcification were each documented in 4 (28.6\%), while pulmonary hypertension was documented in 6 (42.9\%) cases. 


\subsection{Medication}

The various medications prescribed are illustrated in Table 1. Angiotensin converting enzyme inhibitor was prescribed in 22 (95.7\%) of patients, while 21 (91.3\%) were on beta blockers. Aspirin and clopidogrel were prescribed in 13 (56.5\%) and 5 (21.7\%) of patients respectively. Digoxin was used by 14 (60.9\%), whereas furosemide and spironolactone were prescribed to 21 (92.3\%) and 16 (69.6\%) of the victims respectively. Warfarin was prescribed to $6(26.1 \%)$ whereas enoxaparin and statins were each prescribed to 11 (47.8\%) of patients. only $1(4.3 \%)$ was treated with streptokinase for STEACS. Dihydropyridine calcium channel blockers were used for the treatment of hypertension in 6 (26.1\%).

\section{Discussion}

Our findings highlight the significance of SCD as a major contributor of mortality among patients with cardiovascular diseases in a Nigerian tertiary hospital. This, to our knowledge, is the first clinical study on SCD among patients admitted with cardiovascular diseases in a Nigerian tertiary hospital. The findings of nearly equal number of male and female victims of SCD in our series differed from numerous studies showing male preponderance because of higher prevalence of CAD in males [16] [17]. However, the higher prevalence of ICM among males in our series concurs with these assertions. In addition, there were more females admitted during the period under review than males. The most common etiology among those aged 20 - 30 years are PPCM and RHD. This is generally indicative of the burden of PPCM (being a disease of females of child-bearing age) and RHD in the younger population. Peripartum cardiomyopathy is a leading cause for heart failure admission among young women in our center (unpublished data). The high rate of ICM among victims in the age bracket 31 - 40 was driven by events in three males that suffered acute myocardial infarction in their late thirties.

The proportion of SCD from ICM surpassed other etiologies. This is similar to reports from western and Asian countries with a high prevalence of coronary artery disease (CAD) [12] [18], but starkly contrasted with reports from other parts of Nigeria where HHD was reported to be the leading cause [8]-[10]. The high proportion of SCD from ischemic etiology reflects the increasing burden of CAD as reflected in studies from other parts of the country [19], as well as pattern of admission for cardiovascular diseases in our hospital (unpublished data). There are reports indicating that CAD is the most common cause of SCDs in many areas of the world with low prevalence of atherosclerosis [20]. With improved access to healthcare and reduction in communicable diseases in third-world countries, coronary atherosclerosis will emerge as a leading cause of morbidity and mortality [21]. It is disturbing to note that $50 \%$ of deaths resulting from ICM occurred in individuals 40 years and below. This contrasted with the Ile-Ife experience, where the age of SCD victims from ICM ranged between 41 and 60 years [8]. The socioeconomic status of the victims of SCD from ischemic etiology in our center also differs from the Ile-Ife experience. Whereas they reported $100 \%$ of their victims of ischemic SCD to be of high socio-economic class, $4 / 6$ (66.7\%) of our cases belonged to the low socio-economic class. This underscores the fading dividing role of socio-economic background in the etiology of CAD.

The most prevalent co-morbidities amongst victims of ICM were hypertension (83\%) and diabetes mellitus (50\%), with 50\% having both. Hypertension and diabetes are independent risk factors for ICM and SCD, and their co-existence confers more than an additive influence on the risk of CAD [22]. The high prevalence of hypertension among the victims is similar to what was reported in Ile-Ife [8].

The second most prevalent etiology in our series was PPCM, which accounted for about $22 \%$ of cases. Although described as a fairly uncommon problem in the west, PPCM is among the leading causes of hospitalization for heart failure in our practice (unpublished data), as well as other parts of Nigeria [23] [24]. Arrhythmias and SCD can occur in the setting of PPCM [25]. None of the available Nigerian studies reported SCD from PPCM. The severity of LV remodeling and systolic dysfunction (an important prognosticator for SCD) in our cases might have contributed to the large number of SCD.

Non-ischemic DCM resulted in a higher prevalence of 17.3\% (idiopathic DCM in 13.0\% and alcoholic DCM in 4.3\%). Idiopathic DCM remains a leading cause of cardiovascular disease in Africa, and an important cause of SCD [26] [27]. Although the prevalence of SCD among patients with DCM is variable, it results in an approximate $10 \%$ of cases of SCD [12] with an annual mortality rate of $10 \%-50 \%$ depending on functional class [13]. In a review of 14 studies made up of 1432 subjects with DCM, SCD was responsible for $28 \%$ of deaths [28]. Ventricular tachyarrhythmia (predominantly VT) constitutes the most common mode of death although bradyarrhythmia and electromechanical dissociation have been reported, especially in patients with advanced 
LV systolic dysfunction [29]. Non-sustained ventricular tachycardia identifies patients at increased risk of SCD.

The spectrum of valvular heart diseases observed included mixed mitral regurgitation and stenosis, aortic regurgitation, and mixed aortic stenosis and regurgitation. Sudden cardiac death was common in progressive aortic stenosis, but declined with the advent of surgical therapy [2]. However, progressive LV dysfunction in advanced valvular heart disease could have resulted in ventricular arrhythmia/SCD. One of the victims had SBE with a huge vegetation on the aortic valve, and showed remarkable clinical improvement on antibiotics before dying suddenly in a grocery store. In a study of native Egyptians managed with SBE, Al-Mogheer et al. reported a prevalence of $1.7 \%$ for SCD [30]. There are reports of coronary embolization of vegetation from the aortic valve of patients with SBE resulting in acute myocardial infarction [31] [32]. However, the exact mechanism in our patient cannot be ascertained because it occurred out of hospital and there was no autopsy.

Left ventricular dysfunction regardless of etiology has been consistently reported to be a risk factor for SCD [33]. This is demonstrated in our study with about $83 \%$ of all victims having heart failure and $57 \%$ of those with available echo reports having an $\mathrm{EF}$ of $<35 \%$. Although being in a better functional class confers lower risk for overall mortality, a larger proportion of death in those with better NYHA class is due to SCD [34]. This is demonstrated in our series with $61 \%$ of all victims with heart failure being in NYHA class I and II. Although prodromal symptoms are neither sensitive, nor specific predictors of an impending SCD [2], history of palpitation, chest pain and syncope were documented in some of the victims. Sudden onset of these premonitory symptoms and other manifestations of arrhythmia precedes the onset of cardiac arrest, defining the one-hour onset of terminal events in the temporal perspectives of SCD.

Hypertension is a well-documented risk factor for coronary artery disease and SCD [2]. Although present in about $48 \%$ of all victims in our study, a larger proportion of about $89 \%$ of all cases from myocardial infarction had hypertension. The preponderance of MI as etiology of SCD in our series starkly contrasted with reports from other parts of Nigeria, where the dominant hypertension-related cause was hypertensive heart disease, defined as presence of left ventricular hypertrophy (LVH) [8]-[10]. However, the spectrum of hypertensive heart disease includes $\mathrm{LVH}, \mathrm{CAD}$, conduction system disease, systolic and diastolic myocardial dysfunction that may culminate in angina or MI, cardiac arrhythmias and CHF [35]. Although LVH confers an independent mortality risk, it can coexist with acute or chronic myocardial ischemia thereby potentiating the risk of SCD [2].

The most common abnormality observed on ECG was sinus tachycardia, documented in $91 \%$ of available ECGs. A resting heart rate of $>90 \mathrm{bpm}$ identifies patients at increased risk of SCD [12]. Prolonged duration of the QRS complex has been adjudged to be associated with increased risk of SCD [36]. Broad QRS complex consistent with complete left bundle branch block was observed in 19\%. All cases of prolongation of the QT interval in our study were observed in females receiving furosemide for heart failure. Common electrolyte derangements associated with prolongation of the QT interval and arrhythmias are hypokalemia, hypocalcemia and hypomagnesemia; and all could result from use of furosemide [37]. Although none of the victims had Holter ECG, non-sustained VT was observed on routine 12-lead ECG of one victim with DCM. Non-sustained VT has been shown to confer high risk of SCD in patients with structural heart disease [38].

Beta blockers, angiotensin converting enzyme (ACE) inhibitors, spironolactone and statins have been shown to reduce the risk of sudden cardiac arrest and SCD in patients with LV dysfunction of ischemic and nonischemic etiology [39]-[41]. More than $90 \%$ of the victims in our series were placed on beta blockers and angiotensin converting enzyme inhibitors; and spironolactone and statin prescribed in about $70 \%$ and $48 \%$ respectively. This trend reflects the general pattern of heart failure treatment in our center, and is based on recommendations enshrined in practice guidelines. However, most patients presenting with heart failure in our practice present lately with more advanced diseases. In addition, disease-specific therapy like revascularization for IHD, valve replacement therapy and CRT/ICD are not available in our center. Optimum benefit of pharmacologic therapy is more likely if specific treatments of disorders like CAD (with revascularization) and valvular heart diseases (with valve surgeries) are offered. These are largely unavailable in most centers and could probably be responsible for the large burden of SCD despite medical treatment.

All victims of in-hospital sudden cardiac arrest had "compression-only" CPR with a success rate of $7.1 \%$ involving a $40 \mathrm{yr}$ female with acute MI that developed SCA while being evaluated by the cardiologist. This is rather dismal, compared with a success rate of between $20 \%$ and $25 \%$ in developed countries depending on the setting where cardiac arrest occurs [42]. The poor outcome may be related to lack of standing protocol for resuscitation in our center, coupled with inadequate training of staff on resuscitation of cardiac arrest victims. None of the out-of-hospital cases had an attempt at resuscitation. This is not surprising, given the lack of awareness 
and the knowledge of bystander resuscitation.

A number of studies have validated the effectiveness of implantable cardioverter-defibrillator (ICD) in preventing SCD in high risk patients. The Multicenter Automatic Defibrillator Implantation trial (MADIT) showed survival benefit of ICD in patients with ischemic cardiomyopathy and left ventricular ejection fraction of $35 \%$ or less [43]. The MADIT-II study revealed survival benefit following myocardial infarction in patients with poorer ventricular function (EF $\leq 30 \%$ ) [44]. In patients with non-ischemic cardiomyopathy and LVEF < 36\%, the Defibrillators in Non-ischemic Cardiomyopathy treatment Evaluation study (DEFINITE) showed reduced risk of SCD [38]. The Sudden Cardiac Death in Heart Failure Trial (SCD-Heft) evaluated the benefit of ICD in patients with both ischemic and nonischemic cardiomyopathy with LVEF $\leq 35 \%$ and NYHA II/III receiving optimum medical therapy, and showed a greater survival benefit in ICD group compared with amiodarone or placebo [45]. Despite the increasing number of our patients qualifying for prophylactic therapy using ICD, this is largely unavailable in the country and most of sub-Saharan Africa.

\section{Conclusion}

Despite the growing scourge of cardiovascular diseases and its consequences in sub-Saharan Africa, the care of patients with cardiovascular diseases remains suboptimal, with many patients passing through the natural history of their diseases. Our study highlighted the significant role played by ICM in the etiology of SCD. This reflects the increasing scourge of CAD, a disease previously considered a rarity in sub-Saharan Africa. Peripartum cardiomyopathy stands out as the most common form of nonischemic cardiomyopathy resulting in SCD. This, to our knowledge, is the first of such report in the etiology of SCD. Although largely reported as uncommon in the west, PPCM constitutes the majority of the etiology of heart failure in females of child bearing age group in our practice. Our study underscores the need for rapid improvement in care of patients with heart disease if the impending epidemic is to be halted, or reduced to minimum.

\section{Limitations}

Our study has a number of limitations. The initial evaluation of patients with suspected myocardial infarction did not include cardiac troponins in the majority. The few that had cardiac troponins checked was by using point of care testing kits donated from Saudi Arabia that were largely exhausted before the start of the study. Secondly, not all cases of out of hospital death were captured, largely due to migration occasioned by the ongoing insurgency, interruption in telecommunications because of ongoing state of emergency and incessant strike action by hospital workers. None of the victims had autopsy or toxicology/drug level assessments, and terminal events preceding death were not captured on telemetry. These limitations notwithstanding, we believe the study has provided some insight into prevalence and etiology of SCD among our population of patients with cardiovascular diseases.

\section{Conflict of Interest}

The authors declare no competing interest.

\section{Acknowledgements}

We wish to acknowledge the assistance of the technical staff of the cardiology unit, the nursing staff and the medical records staff of the University of Maiduguri Teaching Hospital, for their assistance in the conduct of this study.

\section{References}

[1] Mendis, S., Puska, P. and Norrving, B., Eds. (2011) Global Atlas on cardiovascular Disease Prevention and Control. World Health Organization, Geneva. http://www.who.int/cardiovascular diseases/publications/atlas cvd/en/

[2] Myerburg, R.J. and Castellanos, A. (2012) Cardiac Arrest and Sudden Cardiac Death. In: Bonow, R.O., Mann, D.L., Zipes, D.P., Libby, P. and Braunwald, E., Eds., Braunwald's Heart Disease: A Textbook of Cardiovascular Medicine, Elsevier Saunders, Philadelphia, 845-884. http://dx.doi.org/10.1016/B978-1-4377-0398-6.00041-X

[3] Chugh, S.S., Teodorescu, C., Evanado, A. and Reiner, K. (2010) Sudden Unexplained Death in the Community. In: Brugada, R., Brugada, J. and Brugada, P., Eds., Clinical Approach to Sudden Cardiac Death Syndromes, Springer- 
Verlag, London, 1-6. http://dx.doi.org/10.1007/978-1-84882-927-5_1

[4] Devreedeswagemakers, J.J.M., Gorgels, A.P.M., Duboisarbouw, W.I., Vanree, J.W., Daemen, M., Houben, L.G.E. and Wellens, H.J.J. (1997) Out-of-Hospital Cardiac Arrest in the 1990s: A Population-Based Study in the Maastricht Area on Incidence, Characteristics and Survival. Journal of the American College of Cardiology, 30, 1500-1505. http://dx.doi.org/10.1016/S0735-1097(97)00355-0

[5] Rosamond, W., Flegal, K., Furie, K., Go, A., Greenlund, K., Haase, N., et al. (2008) Heart Disease and Stroke Statistics-2008 Update-A Report from the American Heart Association Statistics Committee and Stroke Statistics Subcommittee. Circulation, 117, E25-E146. http://dx.doi.org/10.1161/CIRCULATIONAHA.107.187998

[6] Myerburg, R.J. (2001) Sudden Cardiac Death: Exploring the Limits of Our Knowledge. Journal of Cardiovascular Electrophysiology, 12, 369. http://dx.doi.org/10.1046/j.1540-8167.2001.00369.x

[7] Mehra, R. (2007) Global Public Health Problem of Sudden Cardiac Death. Journal of Electrocardiology, 40, S118S122. http://dx.doi.org/10.1016/j.jelectrocard.2007.06.023

[8] Rotimi, O., Fatusi, A.O. and Odesanmi, W.O. (2004) Sudden Cardiac Death in Nigerians-The Ile-Ife Experience. West African Journal of Medicine, 23, 27-31. http://dx.doi.org/10.4314/wajm.v23i1.28076

[9] Amakiri, C.N.T. (1995) A Prospective Study of Coroner’s Autopsies in the University College Hospital, Ibadan, Nigeria. Dissertation, Nigerian National Postgraduate Medical College for the Part II Fellowship Examinations.

[10] Akinwusi, P.O., Komolafe, A.O., Olayemi, O.O. and Adeomi, A.A. (2013) Pattern of Sudden Death at Ladoke Akintola University of Technology Teaching Hospital, Osogbo, South West Nigeria. Vascular Health and Risk Management, 9, 333-339. http://dx.doi.org/10.2147/VHRM.S44923

[11] Mandong, B.M., Manasseh, A.N. and Ugwu, B.T. (2006) Medico-Legal Autopsies in North Central Nigeria. East African Medical Journal, 83, 626-630.

[12] Zipes, D.P. and Wellens, H.J.J. (1998) Sudden Cardiac Death. Circulation, 98, 2334-2351. http://dx.doi.org/10.1161/01.CIR.98.21.2334

[13] Mcmurray, J.J.V., Adamopoulos, S., Anker, S.D., Auricchio, A., Bohm, M., Dickstein, K., et al. (2012) ESC Guidelines for the Diagnosis and Treatment of Acute and Chronic Heart Failure 2012: The Task Force for the Diagnosis and Treatment of Acute and Chronic Heart Failure 2012 of the European Society of Cardiology. Developed in Collaboration with the Heart Failure Association (HFA) of the ESC. European Heart Journal, 33, 1787-1847. http://dx.doi.org/10.1093/eurheartj/ehs104

[14] Sliwa, K., Hilfiker-Kleiner, D., Petrie, M.C., Mebazaa, A., Pieske, B., Buchmann, E., et al. (2010) Current State of Knowledge on Aetiology, Diagnosis, Management, and Therapy of Peripartum Cardiomyopathy: A Position Statement from the Heart Failure Association of the European Society of Cardiology Working Group on Peripartum Cardiomyopathy. European Journal of Heart Failure, 12, 767-778. http://dx.doi.org/10.1093/eurjhf/hfq120

[15] Remenyi, B., Wilson, N., Steer, A., Ferreira, B., Kado, J., Kumar, K., et al. (2012) World Heart Federation Criteria for Echocardiographic Diagnosis of Rheumatic Heart Disease-An Evidence-Based Guideline. Nature Reviews Cardiology, 9, 297-309. http://dx.doi.org/10.1038/nrcardio.2012.7

[16] Sung, R.J., Kuo, C.T., Wu, S.N., Lai, W.T., Luqman, N. and Chan, N.Y. (2008) Sudden Cardiac Death Syndrome: Age, Gender, Ethnicity, and Genetics. Acta Cardiologica Sinica, 24, 65-74.

[17] Kanel, W.B., Wison, P.W., D’Agostino, R.B. and Cobb, J. (1998) Sudden Coronary Death in Women. American Heart Journal, 136, 205-212. http://dx.doi.org/10.1053/hj.1998.v136.90226

[18] Myerburg, R.J. (1987) Sudden Cardiac Death: Epidemiology, Causes and Mechanisms. Cardiology, 74, 2-9. http://dx.doi.org/10.1159/000174281

[19] Sani, M.U., Adamu, B., Mijinyawa, M.S., Abdu, A., Karaye, K.M., Maiyaki, M.B. and Borodo, M.M. (2006) Ischaemic Heart Disease in Aminu Kano Teaching Hospital, Kano, Nigeria: A 5 Year Review. Nigerian Journal of Medicine, 5, 128-131. http://dx.doi.org/10.4314/njm.v15i2.37095

[20] Tunstall-Pedoe, H., Ed. (2003) MONICA Monograph and Multimedia Sourcebook: World’s Largest Study of Heart Disease, Stroke, Risk Factors and Population Trends, 1979-2002. World Health Organization, Geneva. http://www.who.int/cardiovascular_diseases/media/en/intro.pdf

[21] Nabel, E.G., Stevens, S. and Smith, R. (2009) Combating Chronic Disease in Developing Countries. The Lancet, 373, 2004-2006. http://dx.doi.org/10.1016/S0140-6736(09)61074-6

[22] Stamler, J., Neaton, J.D., Cohen, J.D., Cutler, J., Eberly, L., Grandits, G., et al. (2012) Multiple Risk Factor Intervention Trial Revisited: A New Perspective Based on Nonfatal and Fatal Composite Endpoints, Coronary and Cardiovascular, during the Trial. Journal of the American Heart Association, 1, Article ID: e003640. http://dx.doi.org/10.1161/JAHA.112.003640

[23] Isezuo, S.A. and Abubakar, S.A. (2007) Epidemiologic Profile of Peripartum Cardiomyopathy in a Tertiary Care Hos- 
pital. Ethnicity and Disease, 17, 228-233.

[24] Davidson, N.M. and Parry, E.H.O. (1978) Peripartum Cardiac Failure. Quarterly Journal of Medicine, 188, $431-463$.

[25] Diao, M., Diop, I.B., Kane, A., Camara, A., Sarr, M., Ba, S.A. and Diouf, S.M. (2004) Electrocardiographic Recording of Long Duration (Holter) of 24 Hours during Idiopathic Cardiomyopathy of the Peripartum. Archives des Maladies du Cour et des Vaisseaux, 97, 25-30.

[26] Maharaj, B. (1991) Causes of Congestive Heart Failure in Black Patients at King Edward VIII Hospital, Durban. Cardiovascular Journal of Africa, 2, 31-32.

[27] Amoah, A.G. and Kallen, C. (2000) Aetiology of Heart Failure as Seen from a Cardiac Referral Centre in Africa. Cardiology, 93, 11-18. http://dx.doi.org/10.1159/000006996

[28] Tamburo, P. and Wilber, D. (1992) Sudden Death in Idiopathic Dilated Cardiomyopathy. American Heart Journal, 124, 1035-1045. http://dx.doi.org/10.1016/0002-8703(92)90989-9

[29] John, R.M., Tedrow, U.B., Koplan, B.A., Albert, C.M., Epstein, L.M., Sweeney, M.O., et al. (2012) Ventricular Arrhythmias and Sudden Cardiac Death. The Lancet, 380, 1520-1529. http://dx.doi.org/10.1016/S0140-6736(12)61413-5

[30] Al-Mogheer, B., Ammar, W., Bakoum, S., Elarousy, W. and Rizk, H. (2013) Predictors of in Hospital Mortality in Patients with Infective Endocarditis. The Egyptian Heart Journal, 65, 159-162. http://dx.doi.org/10.1016/j.ehj.2012.09.002

[31] Roxas, C.J. and Weekes, A.J. (2011) Acute Myocardial Infarction Caused by Coronary Embolism from Infective Endocarditis. Journal of Emergency Medicine, 40, 509-514. http://dx.doi.org/10.1016/j.jemermed.2007.12.041

[32] Jeremias, A., Casserly, I., Estess, J.M., Smedira, N.G. and Topol, E.J. (2001) Acute Myocardial Infarction after Aortic Valve Endocarditis. American Journal of Medicine, 110, 417-418. http://dx.doi.org/10.1016/S0002-9343(00)00751-8

[33] Myerburg, R.J. (2008) Implantable Cardioverter-Defibrillators after Myocardial Infarction. New England Journal of Medicine, 359, 2245-2253. http://dx.doi.org/10.1056/NEJMra0803409

[34] Cleland, J.G., Chattopadhyay, S., Khan, A., Houghton, T. and Kaye, G.C. (2002) Prevalence and Incidence of Arrhythmias and Sudden Death in Heart Failure. Heart Failure Reviews, 7, 229-242. http://dx.doi.org/10.1023/A:1020024122726

[35] Riaz, K. and Ali, Y.S. (2013) Hypertensive Heart Disease. Medscape. http://emedicine.medscape.com/article/162449

[36] Bansch, D., Antz, M., Boczor, S., Volkman, M., Tebbenjohanns, J., Seidl, K., et al. (2002) Primary Prevention of Sudden Cardiac Death in Idiopathic Dilated Cardiomyopathy: The Cardiomyopathy Trial (CAT). Circulation, 105, 14531458. http://dx.doi.org/10.1161/01.CIR.0000012350.99718.AD

[37] Zimetbaum, P.J. and Josephson, M.E., Eds. (2009) Practical Clinical Electrophysiology. Lippincott Williams \& Wilkins, Philadelphia, 193-218.

[38] Kadish, A., Dyer, A., Daubert, J.P., Quigg, R., Estes, N.A.M., Anderson, K.P., et al. (2004) Prophylactic Defibrillator Implantation in Patients with Nonischemic Dilated Cardiomyopathy. New England Journal of Medicine, 350, 21512158. http://dx.doi.org/10.1056/NEJMoa033088

[39] Zipes, D.P., Camm, A.J., Borggrefe, M., Buxton, A.E., Chaitman, B., Fromer, M., et al. (2006) ACC/AHA/ESC 2006 Guidelines for Management of Patients with Ventricular Arrhythmias and the Prevention of Sudden Cardiac Death: A Report of the American College of Cardiology/American Heart Association Task Force and the European Society of Cardiology Committee for Practice Guidelines (Writing Committee to Develop Guidelines for Management of Patients with Ventricular Arrhythmias and the Prevention of Sudden Cardiac Death): Developed in Collaboration with the European Heart Rhythm Association and the Heart Rhythm Society. Circulation, 114, E385-E484. http://dx.doi.org/10.1161/CIRCULATIONAHA.106.178233

[40] Domanski, M.J., Exner, D.V., Borkowf, C.B., Geller, N.L., Rosenberg, Y. and Pfeffer, M.A. (1999) Effect of Angiotensin Converting Enzyme Inhibition on Sudden Cardiac Death in Patients Following Acute Myocardial Infarction: A Meta-Analysis of Randomized Clinical Trials. Journal of American College of Cardiology, 33, 598-604. http://dx.doi.org/10.1016/S0735-1097(98)00609-3

[41] Pitt, B., Zannad, F., Remme, W.J., Cody, R., Castaigne, A., Perez, A., Palensky, J. and Wittes, J. (1999) The Effect of Spironolactone on Morbidity and Mortality in Patients with Severe Heart Failure. New England Journal of Medicine, 341, 709-717. http://dx.doi.org/10.1056/NEJM199909023411001

[42] Rakic, D., Rumboldt, Z., Carevic, V., Bagatin, J., Polic, S., Pivac, N., et al. (2005) In-Hospital Cardiac Arrest and Resuscitation Outcomes: Rationale for Sudden Cardiac Death Approach. Croatian Medical Journal, 46, 907-912.

[43] Moss, A.J., Hall, W.J., Cannom, D.S., Daubert, J.P., Higgins, S.L., Klein, H., et al. (1996) Improved Survival with an Implanted Defibrillator in Patients with Coronary Disease at High Risk for Ventricular Arrhythmia. New England Journal of Medicine, 335, 1933-1940. http://dx.doi.org/10.1056/NEJM199612263352601

[44] Moss, A.J., Zareba, W., Hall, W.J., Klein, H., Wilber, D.J., Cannom, D.S., et al. (2002) Prophylactic Implantation of a 
Defibrillator in Patients with Myocardial Infarction and Reduced Ejection Fraction. New England Journal of Medicine, 346, 877-883. http://dx.doi.org/10.1056/NEJMoa013474

[45] Bardy, G.H., Lee, K.L., Mark, D.B., Poole, J.E., Packer, D.L., Boineau, R., et al. (2005) Amiodarone or an Implantable Cardioverter-Defibrillator for Congestive Heart Failure. New England Journal of Medicine, 352, 225-237.

http://dx.doi.org/10.1056/NEJMoa043399 